\title{
Article
}

\section{Variation of the Three-Dimensional Femoral J-Curve in the Native Knee}

\author{
Sonja A. G. A. Grothues *(D) and Klaus Radermacher
}

Citation: Grothues, S.A.G.A.; Radermacher, K. Variation of the Three-Dimensional Femoral J-Curve in the Native Knee. J. Pers. Med. 2021, 11, 592. https://doi.org/10.3390/ jpm11070592

Academic Editor: Maximilian Rudert

Received: 18 May 2021

Accepted: 16 June 2021

Published: 23 June 2021

Publisher's Note: MDPI stays neutral with regard to jurisdictional claims in published maps and institutional affiliations.

Copyright: (c) 2021 by the authors. Licensee MDPI, Basel, Switzerland. This article is an open access article distributed under the terms and conditions of the Creative Commons Attribution (CC BY) license (https:/ / creativecommons.org/licenses/by/ $4.0 /)$.
Chair of Medical Engineering, Helmholtz Institute for Biomedical Engineering, RWTH Aachen University, 52074 Aachen, Germany; radermacher@hia.rwth-aachen.de

* Correspondence: grothues@hia.rwth-aachen.de

\begin{abstract}
The native femoral J-Curve is known to be a relevant determinant of knee biomechanics. Similarly, after total knee arthroplasty, the J-Curve of the femoral implant component is reported to have a high impact on knee kinematics. The shape of the native femoral J-Curve has previously been analyzed in 2D, however, the knee motion is not planar. In this study, we investigated the J-Curve in 3D by principal component analysis (PCA) and the resulting mean shapes and modes by geometric parameter analysis. Surface models of 90 cadaveric femora were available, 56 male, 32 female and two without respective information. After the translation to a bone-specific coordinate system, relevant contours of the femoral condyles were derived using virtual rotating cutting planes. For each derived contour, an extremum search was performed. The extremum points were used to define the 3D J-Curve of each condyle. Afterwards a PCA and a geometric parameter analysis were performed on the medial and lateral 3D J-Curves. The normalized measures of the mean shapes and the aspects of shape variation of the male and female 3D J-Curves were found to be similar. When considering both female and male J-Curves in a combined analysis, the first mode of the PCA primarily consisted of changes in size, highlighting size differences between female and male femora. Apart from changes in size, variation regarding aspect ratio, arc lengths, orientation, circularity, as well as regarding relative location of the 3D J-Curves was found. The results of this study are in agreement with those of previous 2D analyses on shape and shape variation of the femoral J-Curves. The presented 3D analysis highlights new aspects of shape variability, e.g., regarding curvature and relative location in the transversal plane. Finally, the analysis presented may support the design of (patient-specific) femoral implant components for TKA.
\end{abstract}

Keywords: native knee morphology; femoral J-Curve; principal component analysis; geometric parameter analysis

\section{Introduction}

The sagittal shape of the femoral condyles, which is often referred to as J-Curve, is known to be a significant determinant of knee biomechanics [1]. Similarly, in total knee arthroplasty (TKA), the J-Curve of the femoral component is reported to have a high impact on knee kinematics [2] and its relevance is reflected in various implant design philosophies, including single-, dual-, and multi-radius designs. The medial and lateral J-Curve approximate the contours being in contact with the tibial plateaus and thereby they are highly relevant for tibiofemoral articulation. Therefore, the J-Curve is related to relevant motion phenomena of the native knee, such as femoral rollback and medial pivot [1,3]. Those are linked to flexion range of motion [4] and patient satisfaction in general [5]. In addition, the J-Curve or rather its alteration is highly relevant for ligament strain and tension as well as for the resulting tibiofemoral contact forces. With a ligament stiffness of 60-80 N/mm of medial and lateral collateral ligaments (MCL/LCL) [6,7], a local condylar offset compared to the native J-Curve of only $1 \mathrm{~mm}$ will result either in 60-80 N additional lateral and medial tibiofemoral contact force and increased ligament 
strain; or in ligament relaxation and potential (mid-flexion) instability. In addition, first structural damage is occurring in ligaments from about $5 \%$ strain [8]. With an assumed average length of the MCL(LCL) of $100(60) \mathrm{mm}$, a medial (lateral) offset limit would be 5(3) $\mathrm{mm}$ (corresponding to 5\% maximum strain) which would result in additional medial (lateral) forces of $\sim 300-400(180-240) \mathrm{N}$ for an average knee. Taking into account, that knee arthroplasty should not extend ligament strain up to the limits of structural damage, and that loads of $10 \mathrm{~N}$ (corresponding to less than $1 \mathrm{~mm}$ offset) already activate afferent nerves from receptors in the ligaments triggering the knee joint stabilizing muscles (Sojka et al., 1991), we assume, that local J-Curve offset limits would have to be reduced to the range of 1-2 mm maximum. This is in agreement with literature regarding recommendations for varus-valgus laxity between 0.5 and $1 \mathrm{~mm}$ for extension and 0.7-1.2 $\mathrm{mm}$ for flexion [9].

Consequently, the analysis of the native femoral J-Curve is essential for a better understanding of native knee biomechanics and for optimizing the femoral implant component design in TKA. Previous analyses of the femoral J-Curve have focused on its 2D shape in one specific cutting plane or through projection. Most studies used geometrical primitives such as ellipses and circles and fitted them to the respective 2D J-Curve contours for investigation [10-15]. In a previous study, we evaluated the variation in the native femoral J-Curve by principal component analysis (PCA), enabling a more comprehensive investigation of the shape variation [16]. However, due to the 3D nature of knee motion, the restriction to a 2D evaluation remained a limitation of this study. Hiss and Schwerbrock [17] analyzed the condylar extremum points of a cadaveric knees in 3D, by a comprehensive manual analysis. A limitation of their labor-intensive method is that it is not applicable to large sample sizes. A limitation of their analysis was that they neglected the J-Curve's orientation with regard to the mechanical axis, whereby a relevant amount of variation was neglected. Other authors analyzed the tibiofemoral process of contacts e.g., by finite element simulations [18], but did not evaluate the derived points regarding shape variation.

The aim of this study was to investigate the 3D femoral J-Curve of the native knee by principal component and geometric parameter analysis.

\section{Materials and Methods}

\subsection{Patient Datasets}

Bone surface models of 90 cadaveric femora, which have been segmented semiautomatically (control by experts) from CT data (voxel size: $0.49 / 0.53 \mathrm{~mm}$ ), were provided by ConforMIS (ConforMIS Inc., Billerica, MA, USA). Of the 90 cadavers, 56 were male, 32 female, and for two no gender information was available. The bone models showed no osteophytes or other signs of osteoarthritis. All further processing was performed in semiautomatic self-written MATLAB scripts (Version R2018b, The MathWorks, Inc., Natick, MA, USA).

\subsection{Contour Derivation}

First, the bone models were transferred to a bone-specific coordinate system [19]. Left femora were mirrored. In order to determine relevant bony contours, the concept of rotating cutting planes was used, which has been previously applied in the context of surface parametrization $[19,20]$. The concept is depicted in Figure 1A. The transepicondylar axis was used as origin of the cutting planes. Overall 300 cutting planes between extremum points of the articulating areas on the condyles and the trochlea were used (note Figure 1A shows only 18 cutting planes for better visibility of the individual cutting planes). For each cutting plane a cutting contour was derived. Subsequently, for each contour an extremum search was performed, as it can be seen in Figure 1B. Therefore, the contours were transformed to the $x-y$ plane, and extrema (maxima) regarding the $y$-axis were identified. For the contours defined by the extrema, a curvature analysis was performed, in order to determine the boundaries of the articulating area, according to Li et al. [13]. The contours were then cut accordingly and interpolated by 300 equidistant points. 


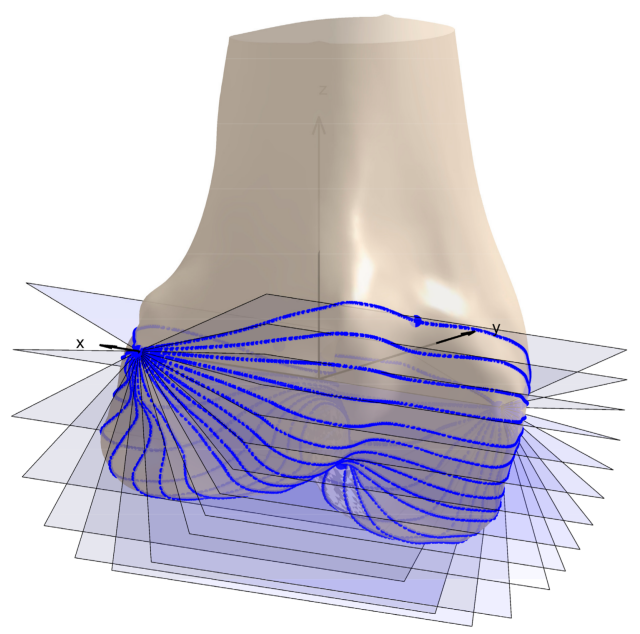

(A)

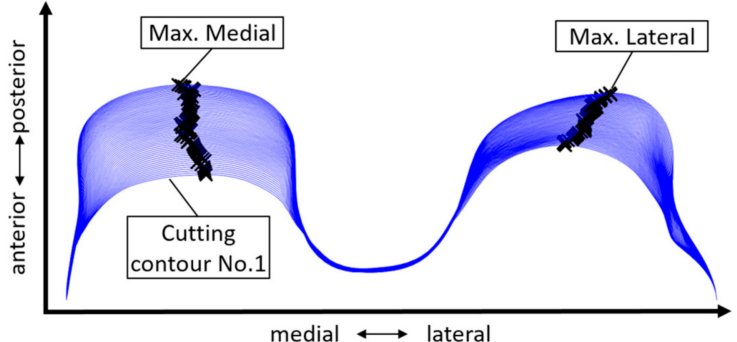

(B)

Figure 1. Elements of the process of contour derivation. (A) Example femur with rotating cutting planes for the derivation of cutting contour (note: only 18 cutting planes displayed here, to enable better visualization of the individual planes). (B) Cutting contours (blue) and extrema (black) for cutting planes 1 to 63.

\subsection{Principal Component Analysis}

Principal component analysis (PCA) is a mathematical method, which is used for reducing dimensionality of multivariate datasets. In PCA, the principal components are calculated, which represent the directions along which the data varies the most. The principal components can be derived by calculating the eigenvectors of the covariance matrix, and they are ordered according to the amount of variance they account for [21].

In the present study, PCA was used to identify dominant patterns of contour variation. PCA requires corresponding data points (landmarks) between the subjects. This is enabled by the use of a consistent bone-specific coordinate system for the contour derivation, and the standardized definition of boundary points. The PCA was performed combined on both the medial and lateral femoral 3D J-Curves. The analysis was performed according to Shlens [22]. The principal modes were defined according to Stegmann and Gomez [23]. The female and male cadavers were analyzed separately as well as combined, in order to evaluate differences in gender.

\subsection{Geometric Parameter Analysis}

A geometric parameter analysis was applied to the mean shape as well as to the first five modes. General size parameters, arc lengths, radii describing the curvature, and the mean and maximum local condylar offsets were considered. The parameters are listed and described in detail in Table 1. In addition, the parameters are displayed in Figure 2. Changes in parameter measures originating from the modes were quantified in absolute deviations and in percent. 
Table 1. Description of the parameters considered in the geometric parameter analysis. Parameters are either defined for the combined overall shape of both J-Curves or individually for the medial and lateral side (column: overall/medial and lateral).

\begin{tabular}{|c|c|c|c|}
\hline $\begin{array}{l}\text { Parameter } \\
\text { Name }\end{array}$ & $\begin{array}{l}\text { Overall/Medial } \\
\text { and Lateral }\end{array}$ & Unit & Description \\
\hline $\begin{array}{l}\text { Mean distal } \\
\text { ML spacing }\end{array}$ & Overall & $\mathrm{mm}$ & $\begin{array}{l}\text { Mean mediolateral distance of the distal points of the } \\
\text { lateral/medial } 3 \mathrm{D} \text { J-Curve }\left(15^{\circ} \text { of extension to } 20^{\circ} \text { of flexion, }\right. \\
\text { reference: radius of the circle fitted to the distal portion of } \\
\text { the condyles). Inspired by Walker [24]. }\end{array}$ \\
\hline $\begin{array}{l}\text { Mean } \\
\text { posterior ML } \\
\text { width }\end{array}$ & Overall & $\mathrm{mm}$ & $\begin{array}{l}\text { Mean mediolateral distance of the posterior points of the } \\
\text { lateral/medial 3D J-Curve }\left(20^{\circ}-120^{\circ} \text { of flexion, reference: }\right. \\
\text { radius of the circle fitted to the posterior portion of the } \\
\text { condyles). Inspired by Mahfouz [25]. }\end{array}$ \\
\hline AP length & $\begin{array}{l}\text { Medial and } \\
\text { lateral }\end{array}$ & $\mathrm{mm}$ & Anteroposterior length of the medial/lateral 3D J-Curve. \\
\hline Distal radius & $\begin{array}{l}\text { Medial and } \\
\text { lateral }\end{array}$ & $\mathrm{mm}$ & $\begin{array}{c}\text { Radius of the circle fitted to the distal portion of the } \\
\text { medial/lateral 3D J-Curve. The calculation was performed } \\
\text { according to Nuno and Ahmed [15] and is described in } \\
\text { more detail in Asseln et al. [26]. }\end{array}$ \\
\hline $\begin{array}{l}\text { Posterior } \\
\text { radius }\end{array}$ & $\begin{array}{l}\text { Medial and } \\
\text { lateral }\end{array}$ & $\mathrm{mm}$ & $\begin{array}{c}\text { Radius of the circle fitted to the posterior portion of the } \\
\text { medial/lateral 3D J-Curve. The calculation was performed } \\
\text { according to Nuno and Ahmed [15] and is described in } \\
\text { more detail in Asseln et al. [26]. }\end{array}$ \\
\hline $\begin{array}{l}\text { Functional arc } \\
\text { length }\end{array}$ & $\begin{array}{l}\text { Medial and } \\
\text { lateral }\end{array}$ & $\mathrm{mm}$ & $\begin{array}{l}\text { Arc length of the medial/lateral 3D J-Curve between } 15^{\circ} \text { of } \\
\text { extension until } 120^{\circ} \text { of flexion (reference: center of the circle } \\
\text { fitted to the distal/posterior portion of the condyles). }\end{array}$ \\
\hline $\begin{array}{l}\text { Arc length } \\
15^{\circ} \text { Ext.-20 } \\
\text { Flex. }\end{array}$ & $\begin{array}{l}\text { Medial and } \\
\text { lateral }\end{array}$ & $\mathrm{mm}$ & $\begin{array}{l}\text { Arc length of the medial/lateral 3D J-Curve between } 15^{\circ} \text { of } \\
\text { extension until } 20^{\circ} \text { of flexion (reference: center of the circle } \\
\text { fitted to the distal portion of the condyles). }\end{array}$ \\
\hline $\begin{array}{l}\text { Arc length } \\
20^{\circ}-120^{\circ} \text { Flex. }\end{array}$ & $\begin{array}{l}\text { Medial and } \\
\text { lateral }\end{array}$ & $\mathrm{mm}$ & $\begin{array}{l}\text { Arc length of the medial/lateral 3D J-Curve between } 20^{\circ} \\
\text { until } 120^{\circ} \text { of flexion (reference: center of the circle fitted to } \\
\text { the distal/ posterior portion of the condyles). }\end{array}$ \\
\hline $\begin{array}{l}\text { Mean abs. } \\
\text { deviation }\end{array}$ & $\begin{array}{l}\text { Medial and } \\
\text { lateral }\end{array}$ & $\mathrm{mm}$ & $\begin{array}{l}\text { Mean absolute deviation (mean condylar offset) regarding } \\
\text { anteroposterior and proximodistal direction. }\end{array}$ \\
\hline $\begin{array}{l}\text { Max abs. } \\
\text { deviation }\end{array}$ & $\begin{array}{l}\text { Medial and } \\
\text { lateral }\end{array}$ & $\mathrm{mm}$ & $\begin{array}{l}\text { Maximum absolute deviation (maximum condylar offset) } \\
\text { regarding anteroposterior and proximodistal direction. }\end{array}$ \\
\hline
\end{tabular}
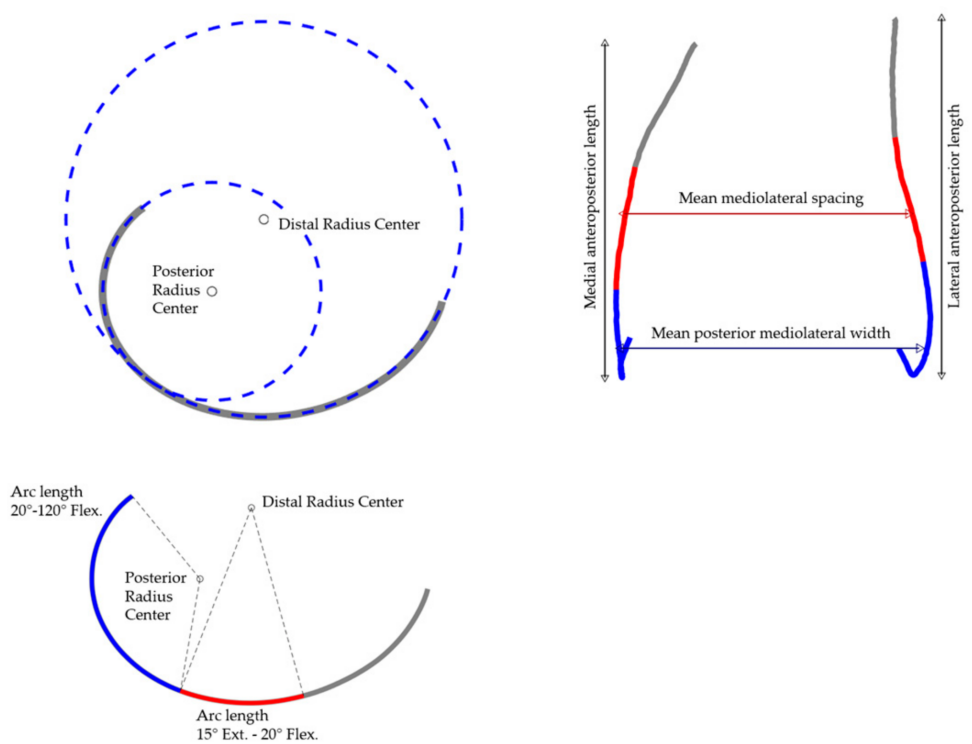

Figure 2. Visualization of the geometric parameter analysis on the example of the mean shape (combined population). 


\section{Results}

In total, 85 of the 90 cadaver cases could be processed without errors (54 male, 29 females, 2 without gender information). Figure 3 shows an example of the derived contours of one femur, together with the respective bone model. An overview of all derived 3D J-Curves is given in Figure 4.

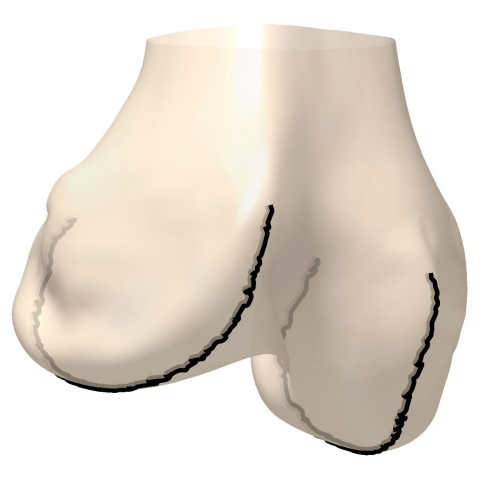

(A)

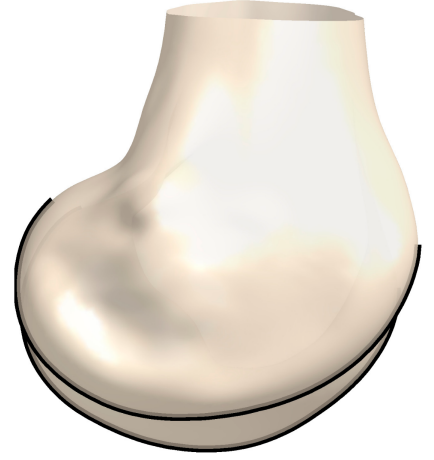

(B)

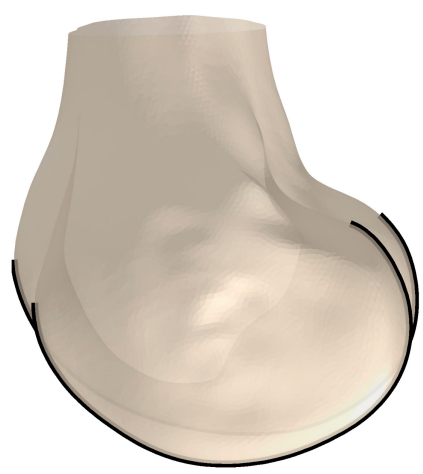

(C)

Figure 3. Example of the derived 3D J-Curve contours. (A) Anterior/lateral-posterior/medial view. (B) Lateral-medial view. (C) Medial-lateral view.

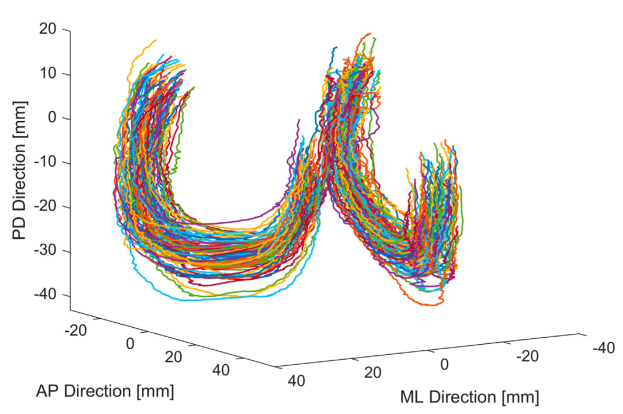

(A)

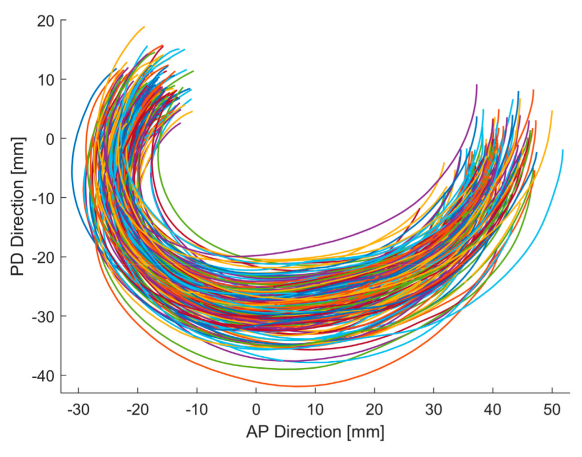

(B)

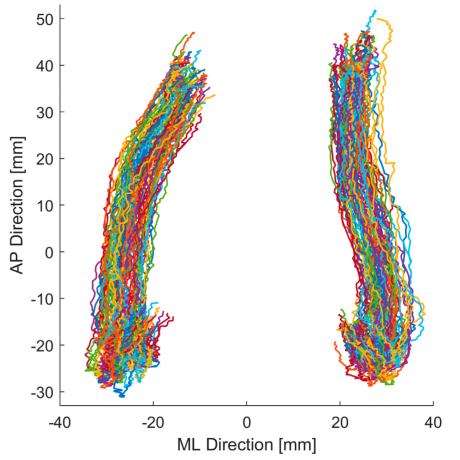

(C)

Figure 4. 3D J-Curve contours of both genders. (A) Anterior/lateral-posterior/medial view. (B) Lateral-medial view. (C) Superior-inferior view.

The mean shapes of the male, female and combined population differed regarding the morphological measures considered (Table 2). However, after normalization of the measures according to their direction of measurement (mediolateral measures by the posterior mediolateral width, anteroposterior measures by the anteroposterior size) as suggested by Asseln et al. [27], those normalized measures were comparable for the male, female and combined population, as it can be seen in Table 2.

The results of the separate PCA of female and male 3D J-Curves showed similarities regarding the aspects of shape variations (e.g., arc lengths, orientation, aspect ratio). For the combined analysis (Figure 5), the first mode consisted almost solely of changes in size, highlighting size differences between female and male femora. Apart from this first mode, the aspects of shape variation were similar for all analyses. Due to similarities in normalized measures of the mean shapes and in the aspects of shape variation, in the following only the detailed results of the combined analysis of both genders are presented.

Figure 5 shows the PCA results regarding the first five modes. The percentage of variation explained by modes $1-5$ were $31.5,23.4,20.1,7.4$, and $5.5 \%$, respectively (sum: $87.8 \%$ ). In Table 3 the results of the respective geometric parameter analysis are presented. 
The first mode involved changes in size, which lead to an increase of all parameters in the geometric parameter analysis, when adding 3 standard deviations to the mean shape (Table 3). Furthermore, for the medial side, also slight changes in 3D J-Curve orientation were associated. With the second mode, the most prominent changes were seen regarding the anterior region of the lateral J-Curve. For the medial side, only slight changes in curvature and size were observed. The third mode consisted of changes in medial J-Curve orientation, in lateral J-Curve size and in mediolateral width. The fourth mode primarily represented changes in aspect ratio. The fifth mode mostly consisted of changes in relative location of the medial vs. the lateral 3D J-Curve.

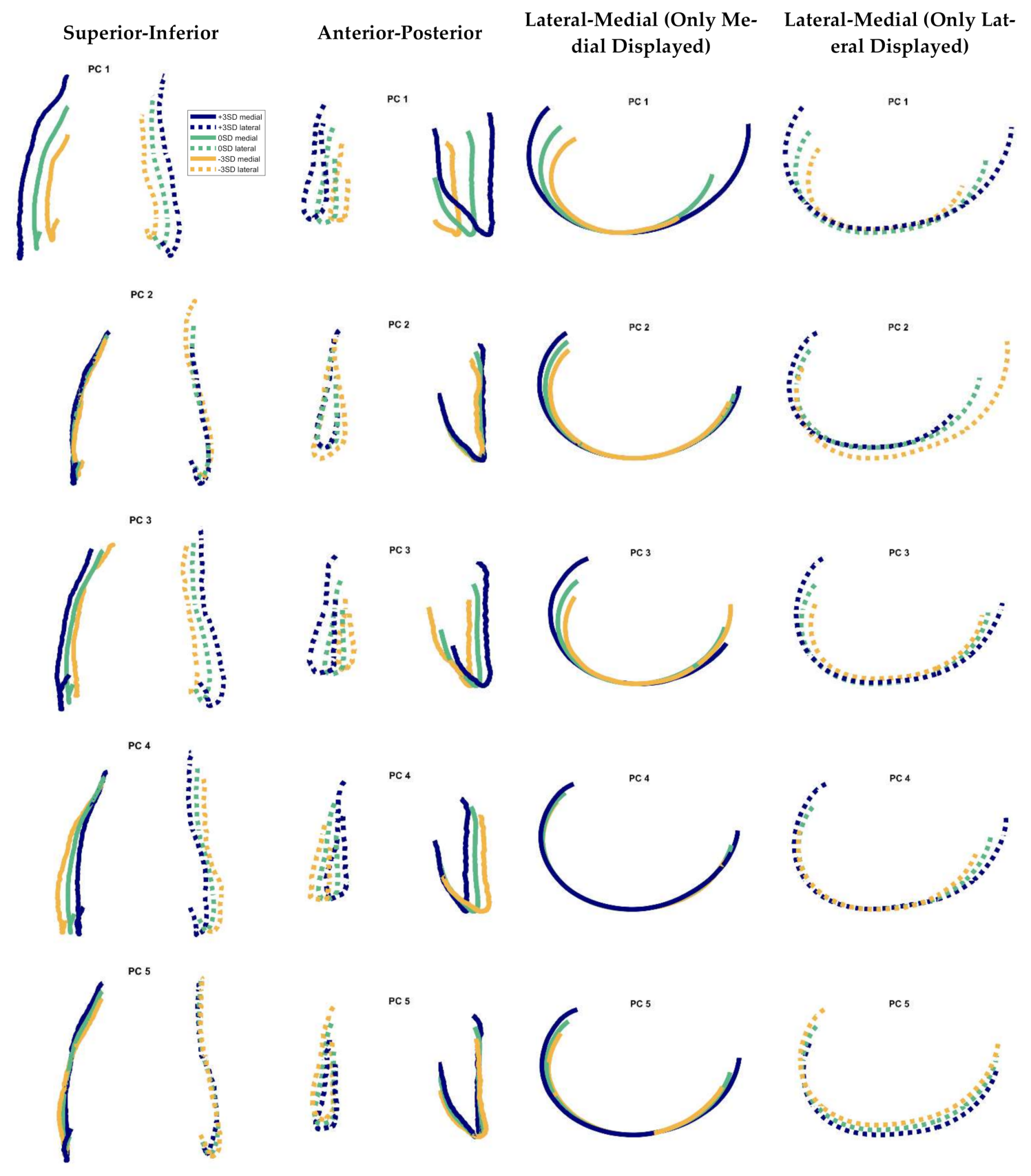

Figure 5. Modes $1-5$ of the cadavers' 3D J-Curves in different views. Solid line: medial, dashed line: lateral. $3 S D=3$ standard deviations. All contours were oriented to their most distal point in proximodistal direction, for better comparison of the respective variance. Variation explained by the modes 1-5: 31.5, 23.4, 20.1, 7.4, and 5.5\%, respectively. 
Table 2. Results of the geometric parameter analysis: measures of the mean shapes of the male, female, and combined population are listed. In addition, normalized measures are given in brackets.

\begin{tabular}{|c|c|c|c|c|c|c|c|c|c|}
\hline $\begin{array}{c}\text { Parameter } \\
\text { (Normalized by } \\
\text { ML/AP) }\end{array}$ & $\begin{array}{l}\text { Mean ML } \\
\text { Spacing }\end{array}$ & $\begin{array}{c}\text { Mean } \\
\text { Posterior } \\
\text { ML Width }\end{array}$ & & AP Length & $\begin{array}{l}\text { Distal } \\
\text { Radius }\end{array}$ & $\begin{array}{l}\text { Posterior } \\
\text { Radius }\end{array}$ & $\begin{array}{l}\text { Funct. Arc } \\
\text { Length }\end{array}$ & $\begin{array}{l}\text { Arc Length } \\
15^{\circ} \text { Ext. }-20^{\circ} \\
\text { Flex. }\end{array}$ & $\begin{array}{l}\text { Arc Length } \\
20^{\circ}-120^{\circ} \\
\text { Flex. }\end{array}$ \\
\hline \multirow{2}{*}{$\begin{array}{l}\text { Mean shape } \\
\text { (combined) }\end{array}$} & \multirow{2}{*}{$\begin{array}{l}51.2 \mathrm{~mm} \\
(0.95)\end{array}$} & \multirow[b]{2}{*}{$53.7 \mathrm{~mm}$} & Lateral & $\begin{array}{c}64.2 \mathrm{~mm} \\
(0.99)\end{array}$ & $\begin{array}{c}48.8 \mathrm{~mm} \\
(0.75)\end{array}$ & $\begin{array}{c}20.3 \mathrm{~mm} \\
(0.31)\end{array}$ & $\begin{array}{c}67.4 \mathrm{~mm} \\
(1.04)\end{array}$ & $\begin{array}{c}32.5 \mathrm{~mm} \\
(0.50)\end{array}$ & $\begin{array}{c}34.9 \mathrm{~mm} \\
(0.54)\end{array}$ \\
\hline & & & Medial & $\begin{array}{c}60.1 \mathrm{~mm} \\
(0.93)\end{array}$ & $\begin{array}{c}35.1 \mathrm{~mm} \\
(0.54)\end{array}$ & $\begin{array}{c}19.3 \mathrm{~mm} \\
(0.30)\end{array}$ & $\begin{array}{c}67.5 \mathrm{~mm} \\
(1.04)\end{array}$ & $\begin{array}{c}22.8 \mathrm{~mm} \\
(0.35)\end{array}$ & $\begin{array}{c}44.7 \mathrm{~mm} \\
(0.69)\end{array}$ \\
\hline \multirow{2}{*}{$\begin{array}{c}\text { Mean shape } \\
\text { (Male) }\end{array}$} & \multirow{2}{*}{$\begin{array}{l}53.7 \mathrm{~mm} \\
(0.96)\end{array}$} & \multirow{2}{*}{$56.1 \mathrm{~mm}$} & Lateral & $\begin{array}{c}66.9 \mathrm{~mm} \\
(0.99) \\
\end{array}$ & $\begin{array}{c}50.5 \mathrm{~mm} \\
(0.75) \\
\end{array}$ & $\begin{array}{c}21.4 \mathrm{~mm} \\
(0.32)\end{array}$ & $\begin{array}{c}69.7 \mathrm{~mm} \\
(1.03) \\
\end{array}$ & $\begin{array}{c}33.7 \mathrm{~mm} \\
(0.50) \\
\end{array}$ & $\begin{array}{c}35.9 \mathrm{~mm} \\
(0.53)\end{array}$ \\
\hline & & & Medial & $\begin{array}{c}62.8 \mathrm{~mm} \\
(0.93)\end{array}$ & $\begin{array}{c}36.9 \mathrm{~mm} \\
(0.55)\end{array}$ & $\begin{array}{c}20.2 \mathrm{~mm} \\
(0.30)\end{array}$ & $\begin{array}{c}70.1 \mathrm{~mm} \\
(1.04)\end{array}$ & $\begin{array}{c}23.9 \mathrm{~mm} \\
(0.36)\end{array}$ & $\begin{array}{c}46.2 \mathrm{~mm} \\
(0.69)\end{array}$ \\
\hline \multirow{2}{*}{$\begin{array}{l}\text { Mean shape } \\
\text { (Female) }\end{array}$} & \multirow{2}{*}{$\begin{array}{l}46.2 \mathrm{~mm} \\
(0.94)\end{array}$} & \multirow{2}{*}{$49.1 \mathrm{~mm}$} & Lateral & $\begin{array}{c}60.5 \mathrm{~mm} \\
(0.99)\end{array}$ & $\begin{array}{c}46.9 \mathrm{~mm} \\
(0.77)\end{array}$ & $\begin{array}{c}18.6 \mathrm{~mm} \\
(0.31)\end{array}$ & $\begin{array}{c}64.0 \mathrm{~mm} \\
(1.05)\end{array}$ & $\begin{array}{c}30.9 \mathrm{~mm} \\
(0.51)\end{array}$ & $\begin{array}{c}33.2 \mathrm{~mm} \\
(0.54)\end{array}$ \\
\hline & & & Medial & $\begin{array}{c}55.2 \mathrm{~mm} \\
(0.91)\end{array}$ & $\begin{array}{c}31.5 \mathrm{~mm} \\
(0.52)\end{array}$ & $\begin{array}{c}17.7 \mathrm{~mm} \\
(0.29)\end{array}$ & $\begin{array}{c}62.9 \mathrm{~mm} \\
(1.03)\end{array}$ & $\begin{array}{c}20.4 \mathrm{~mm} \\
(0.33)\end{array}$ & $\begin{array}{c}42.5 \mathrm{~mm} \\
(0.70)\end{array}$ \\
\hline
\end{tabular}

Table 3. Results of the geometric parameter analysis: Effect sizes for the first five modes are listed (+3SD). Deviations with regard to the mean shape are quantified in millimeter and in percent. Changes exceeding predefined limits are highlighted (color code below). Abbreviations: $\mathrm{AP}=$ anteroposterior, $\mathrm{ML}=$ mediolateral.

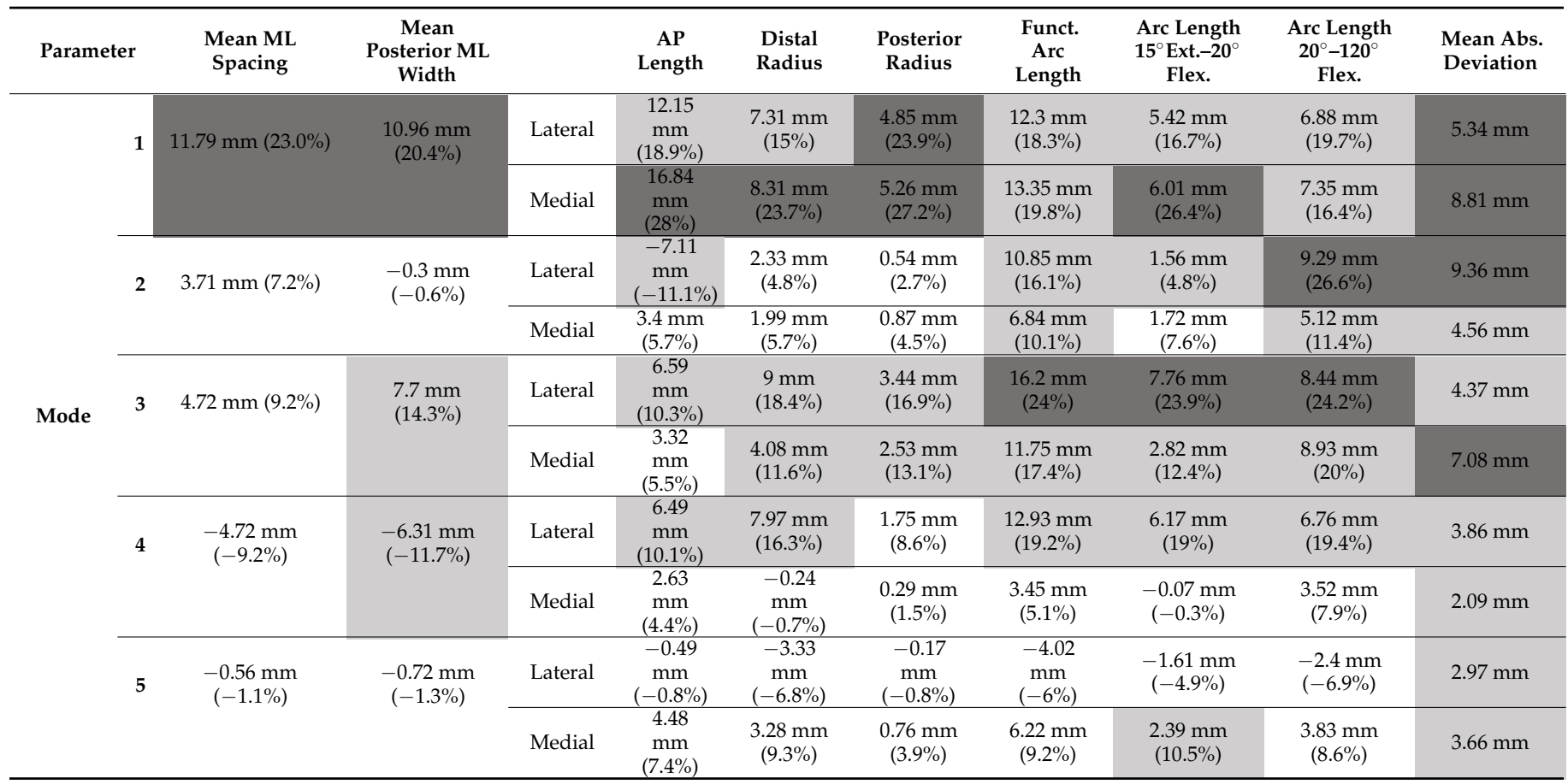

Color code: Deviations: $\geq \pm 10 \%$ : I $\geq \pm 20 \%$ : Mean abs. deviation: $\geq 2 \mathrm{~mm}: \square । \geq 5 \mathrm{~mm}:$

\section{Discussion}

In contrast to previous analyses on the 2D J-Curve shape, the analysis presented enabled the consideration of shape and shape variation in the transversal plane. Compared to a previous study by Hiss and Schwerbrock [17] on femoral J-Curves in 3D, the presented analysis was performed semiautomatically, which enabled the processing of a higher number of femora.

Similar aspects of shape variation of the femoral 3D J-Curves were found in men and in women. The amount of variation explained by changes in size was higher for the combined than for the gender-specific analyses. This is reasonable, as men in general have larger knees compared to women [27]. Hence, the combination of both genders probably is the reason for the increased variability in size.

For the combined analyses, the identified radii of the 3D J-Curve's mean shape are comparable to those of previous studies on the 2D J-Curve $[11,12,15,27]$. Most of the 
parameter values derived in this study are also comparable to a previous study on the $2 \mathrm{D}$ J-Curve by our group [16]. However, a relevant difference regarding the AP length of the medial J-Curve can be seen. The medial 3D J-Curve shows a higher AP length compared to the medial 2D J-Curve. This may be explained by the distribution of the medial condyle's extremum points in the transversal plane (Figure 4C). The extrema of both condyles do not lie in a single sagittal plane. Especially the medial extrema rather form a curve. As for the 2D J-Curve derivation a single sagittal cutting plane was used, parts of the medial J-Curve may have been neglected. This effect may also be present to a lower extent for the lateral side, as the lateral 2D J-Curve is also slightly smaller in AP direction compared to the lateral 3D J-Curve.

The general relevance of morphological parameters for knee kinematics has been shown in a previous study by our group [28]. In the first degrees of flexion, the share of rolling vs. gliding of the femur on the tibia is estimated to be 1:2 [29]. Afterwards, the motion can be characterized as primarily gliding (in late flexion: rolling/gliding 1:4) [29]. Therefore, the arc length in the beginning of flexion is of higher functional relevance, as it represents the primary running surface of the respective condyle and thereby influences the range of tibiofemoral anterior-posterior translation and internal-external rotation. In the PCA results, changes in the distal arc length differed between the medial and lateral side and were even counteracting for modes 4 and 5 (Table 3).

In our study, mean absolute condylar offsets in the range of $2.09-9.36 \mathrm{~mm}$ and local maximum offsets in the range of $2.61-16.0 \mathrm{~mm}$ were found. Those exceed the derived offset limits of $1-2 \mathrm{~mm}$. It has to be noted that with \pm 3 standard deviations, a wide range of variation was considered. However, every patient needs to be provided with an adequate implant. In addition, all mean offsets were larger than $2 \mathrm{~mm}$, suggesting that a relevant share of the patient population may receive an implant with local condylar offsets exceeding those limits. Some of the variation regarding size and aspect ratio is accounted for by different implant sizes and narrow/standard implant versions. Remaining variation, however, is not accounted for with standard implants.

\section{Limitations}

The study presented involved limitations. First, the start and end points of the J-Curves were determined automatically by curvature analysis and not by a visual inspection of the clinical images. However, this automation was necessary in order to enable the processing of a large number of cases.

Second, the use of an extremum search still is an approximation of an actual course of tibiofemoral contact points on the femur. However, the extremum search used in this study identified relevant points on the contours, which correspond to contact points of femoral and tibial implant components in TKA. Therefore, we believe the contours to be of relevance for implant design.

Third, the database is limited to 90 cases of unknown ethnicity. Further analyses are necessary to investigate more cases and evaluate differences between ethnicities. In addition, this study is restricted to the analysis of the femur. Future analyses should also investigate the tibial sagittal contours and the patellofemoral contact (native vs. alloplastic).

Lastly, this study only addresses implant design as one factor with influence on clinical outcome and patient satisfaction in TKA. There are many other potentially relevant influencing factors, such as surgical technique, muscular and ligamentous situation, patient's expectations, etc. However, by optimizing the J-Curve "fit", the potential for superior outcomes may be enabled.

\section{Conclusions}

The results of this study suggest that variation in the native femoral 3D J-Curves does not only involve scaling and aspect ratio changes, but other aspects such as changes in curvature or circularity, arc lengths, and relative location. Current OTS implant manufacturers offer various implant sizes (i.e., scaling only) as well as narrow and wide implants, 
accounting for differences in size and in aspect ratio. Differences in other aspects such as in curvature are not accounted for so far. The industry aims at a better restoration of knee morphology, e.g., by introducing more sizes or gender-specific implants. Hence, for future implant systems it might be valuable not only to consider narrow and standard versions but, e.g., high and low curvature implants as well as versions with different offsets. Taking into account the importance of shape mismatches along the articulating surfaces $[9,30]$ as well as the discrepancy between actual implant designs and patient specific J-Curves [16], the number of additional sizes needed potentially will be very high. Against this background, we agree to the conclusion of Delport et al., that another way could be to customize the implant design to each patient individually [9]. In such cases, however, additional attention to force distribution and contact areas between implant surfaces may be needed, depending upon factors such as the nature and degree of the customization of the implant design.

Due to the relevance of bone morphology for active kinematics, related soft tissue strains and for the overall clinical outcome [1,3-5], patient specific 3D J Curves derived from individual image data could be used to evaluate therapeutic options (OTS implants vs. patient specific implants (intrinsically reflecting patient specific J-Curve shape)) and to decide for an adequate match for each patient individually.

Author Contributions: Conceptualization, S.A.G.A.G. and K.R.; formal analysis, S.A.G.A.G.; writing —original draft, S.A.G.A.G.; writing—review and editing, K.R. All authors have read and agreed to the published version of the manuscript.

Funding: This work was partially supported by ConforMIS, Inc., Billerica, USA (RWTH 419410.0013).

Institutional Review Board Statement: Ethical approval was not required for this study since the surface bone models and associated data used in this investigation were from cadaveric specimens. No donor identifying information was accessed for the conduct of the study.

Informed Consent Statement: Not applicable.

Conflicts of Interest: The funding did not affect the outcome of the study in any respect. The cadaveric specimens were chosen solely based on osteophyte volume. The principal components were ranked and chosen for closer analysis based on the amount of variance explained. ConforMIS had no role in the study design, the collection, analysis and interpretation of data, in the writing of the manuscript or in the decision to submit the manuscript for publication.

\section{References}

1. Klein, P.; Sommerfeld, P. Biomechanik der Menschlichen Gelenke-Biomechanik der Wirbelsäule; Nachdr. d. Aufl von 2004 in 1 Bd; Urban \& Fischer in Elsevier: München, Germany, 2012; ISBN 3437552031.

2. Kessler, O.; Dürselen, L.; Banks, S.; Mannel, H.; Marin, F. Sagittal curvature of total knee replacements predicts in vivo kinematics. Clin. Biomech. (Bristol Avon) 2007, 22, 52-58. [CrossRef] [PubMed]

3. Freeman, M.A.R.; Pinskerova, V. The movement of the normal tibio-femoral joint. J. Biomech. 2005, 38, 197-208. [CrossRef] [PubMed]

4. Pfitzner, T.; Moewis, P.; Stein, P.; Boeth, H.; Trepczynski, A.; von Roth, P.; Duda, G.N. Modifications of femoral component design in multi-radius total knee arthroplasty lead to higher lateral posterior femoro-tibial translation. Knee Surg. Sports Traumatol. Arthrosc. 2018, 26, 1645-1655. [CrossRef] [PubMed]

5. Fantozzi, S.; Catani, F.; Ensini, A.; Leardini, A.; Giannini, S. Femoral rollback of cruciate-retaining and posterior-stabilized total knee replacements: In vivo fluoroscopic analysis during activities of daily living. J. Orthop. Res. 2006, 24, 2222-2229. [CrossRef]

6. Völlner, F.; Weber, T.; Weber, M.; Renkawitz, T.; Dendorfer, S.; Grifka, J.; Craiovan, B. A simple method for determining ligament stiffness during total knee arthroplasty in vivo. Sci. Rep. 2019, 9, 5261. [CrossRef]

7. Wilson, W.T.; Deakin, A.H.; Payne, A.P.; Picard, F.; Wearing, S.C. Comparative analysis of the structural properties of the collateral ligaments of the human knee. J. Orthop. Sports Phys. Ther. 2012, 42, 345-351. [CrossRef]

8. Provenzano, P.P.; Heisey, D.; Hayashi, K.; Lakes, R.; Vanderby, R. Subfailure damage in ligament: A structural and cellular evaluation. J. Appl. Physiol. (1985) 2002, 92, 362-371. [CrossRef]

9. Delport, H.; Labey, L.; de Corte, R.; Innocenti, B.; Vander Sloten, J.; Bellemans, J. Collateral ligament strains during knee joint laxity evaluation before and after TKA. Clin. Biomech. (Bristol Avon) 2013, 28, 777-782. [CrossRef]

10. Biscević, M.; Hebibović, M.; Smrke, D. Variations of femoral condyle shape. Coll. Antropol. 2005, 29, 409-414. 
11. Howell, S.M.; Howell, S.J.; Hull, M.L. Assessment of the radii of the medial and lateral femoral condyles in varus and valgus knees with osteoarthritis. J. Bone Jt. Surg. Am. 2010, 92, 98-104. [CrossRef]

12. Li, K.; Langdale, E.; Tashman, S.; Harner, C.; Zhang, X. Gender and condylar differences in distal femur morphometry clarified by automated computer analyses. J. Orthop. Res. 2012, 30, 686-692. [CrossRef]

13. Li, K.; Tashman, S.; Fu, F.; Harner, C.; Zhang, X. Automating analyses of the distal femur articular geometry based on threedimensional surface data. Ann. Biomed. Eng. 2010, 38, 2928-2936. [CrossRef]

14. Martelli, S.; Pinskerova, V. The shapes of the tibial and femoral articular surfaces in relation to tibiofemoral movement. J. Bone Jt. Surg. Br. 2002, 84, 607-613. [CrossRef]

15. Nuño, N.; Ahmed, A.M. Sagittal profile of the femoral condyles and its application to femorotibial contact analysis. J. Biomech Eng. 2001, 123, 18-26. [CrossRef]

16. Grothues, S.A.G.A.; Asseln, M.; Radermacher, K. Variation of the femoral J-Curve in the native knee. In Proceedings of the 20th Annual Meeting of the International Society for Computer Assisted Orthopaedic Surgery (CAOS 2020), Brest, France, 10-13 June 2020; pp. 86-91.

17. Hiss, E.; Schwerbrock, B. Untersuchungen zur räumlichen Form der Femurkondylen. Z. Orthop. Ihre Grenzgeb. 1980, 118, 396-404. [CrossRef]

18. Gu, W.; Pandy, M. Direct Validation of Human Knee-Joint Contact Mechanics Derived from Subject-Specific Finite-Element Models of the Tibiofemoral and Patellofemoral Joints. J. Biomech. Eng. 2019. [CrossRef]

19. Asseln, M. Morphological and Functional Analysis of the Knee Joint for Implant Design Optimization; [1. Auflage]; Shaker Verlag: Düren, Germany, 2019; ISBN 978-3-8440-7047-7.

20. Asseln, M.; Hänisch, C.; Alhares, G.; Eschweiler, J.; Radermacher, K. Automatic Parameterisation of the Distal Femur Based on 3D Surface Data: A Novel Approach for Systematic Morphological Analysis and Optimisation. In Proceedings of the 15th Annual Meeting of the International Society for Computer Assisted Orthopaedic Surgery (CAOS 2015), Vancouver, BC, Canada, 17-20 June 2015 ; p. 68.

21. Ringnér, M. What is principal component analysis? Nat. Biotechnol. 2008, 26, 303-304. [CrossRef]

22. Shlens, J. A Tutorial on Principal Component Analysis. 2005. Available online: https://www.cs.cmu.edu/ \{\}elaw/papers/pca.pdf (accessed on 14 January 2020).

23. Stegmann, M.B.; Gomez, D.D. A Brief Introduction to Statistical Shape Analysis. 2002. Available online: http://www2.imm.dtu.dk/ pubdb/edoc/imm403.pdf (accessed on 31 May 2021).

24. Walker, P.S. Bearing Surfaces for Motion Control in Total Knee Arthroplasty. In Total Knee Arthroplasty; Bellemans, J., Ries, M.D., Victor, J.M.K., Eds.; Springer: Berlin/Heidelberg, Germany, 2005; pp. 295-302. ISBN 3-540-20242-0.

25. Mahfouz, M.; Abdel Fatah, E.E.; Bowers, L.S.; Scuderi, G. Three-dimensional morphology of the knee reveals ethnic differences. Clin. Orthop. Relat. Res. 2012, 470, 172-185. [CrossRef]

26. Asseln, M.; Fischer, M.C.M.; Chan, H.Y.; Meere, P.; Walker, P.; Radermacher, K. Automatic standardized shape analysis of the sagittal profiles (J-Curves) of the femoral condyles based on three-dimensional (3D) surface data. In Proceedings of the 19th Annual Meeting of the International Society for Computer Assisted Orthopaedic Surgery (CAOS 2019), New York, NY, USA, 19-22 June 2019; pp. 21-25.

27. Asseln, M.; Hänisch, C.; Schick, F.; Radermacher, K. Gender differences in knee morphology and the prospects for implant design in total knee replacement. Knee 2018, 25, 545-558. [CrossRef]

28. Asseln, M.; Grothues, S.A.G.A.; Radermacher, K. Relationship between the form and function of implant design in total knee replacement. J. Biomech. 2021, 119, 110296. [CrossRef] [PubMed]

29. Menschik, A. Biometrie: Das Konstruktionsprinzip des Kniegelenks, des Hüftgelenks, der Beinlänge und der Körpergröße; Springer: Berlin/Heisenberg, Germany, 1987; ISBN 3-540-17737-X.

30. Mihalko, W.M.; Saleh, K.J.; Krackow, K.A.; Whiteside, L.A. Soft-tissue balancing during total knee arthroplasty in the varus knee. J. Am. Acad. Orthop. Surg. 2009, 17, 766-774. [CrossRef] [PubMed] 